\title{
Identifying fish nurseries using density and persistence measures
}

\author{
Francesco Colloca ${ }^{1, *}$, Valerio Bartolino ${ }^{1}$, Giovanna Jona Lasinio ${ }^{2}$, Luigi Maiorano ${ }^{1}$, \\ Paolo Sartor ${ }^{3}$, Giandomenico Ardizzone ${ }^{1}$
}

\author{
${ }^{1}$ Department of Animal and Human Biology, Sapienza University of Rome, V.le dell'Università, 32, 00185 Rome, Italy \\ ${ }^{2}$ Department of Statistics, Probability and Applied Statistics, Sapienza University of Rome, P.le Aldo Moro 5, 00185 Rome, Italy \\ ${ }^{3}$ Interuniversitary Centre of Marine Biology, V.le Nazario Sauro 4, 57128 Livorno, Italy
}

\begin{abstract}
We propose a 3-step methodological approach to identify and classify fish nurseries for fisheries management purposes. We applied our approach to juvenile European hake Merluccius merluccius in the central Mediterranean Sea. Time series of trawl-survey fish-density data were used to map juvenile hake distribution with Bayesian kriging, while geostatistical aggregation curves were used to find density hot-spots. Persistence measures were adopted to identify nurseries on the basis of their spatio-temporal persistence. We found that areas with a high density of juvenile hake showed a high temporal persistence on both a seasonal and annual basis, with the most persistent nursery areas covering about $5 \%$ of the study areas while including about $39 \%$ of hake recruitment (averaged over $10 \mathrm{yr}$ ). We believe the persistence of these areas is indirect evidence of their importance to the productivity of the population, with many potentially important implications for fisheries management. The approach that we developed to identify hake nurseries can be applied to different species and life stages to improve knowledge of the role of habitat for populations and communities.
\end{abstract}

KEY WORDS: Nurseries - Merluccius merluccius · Mediterranean Sea • Bayesian kriging · Geostatistical aggregation curves $\cdot$ Persistence measure

Resale or republication not permitted without written consent of the publisher

\section{INTRODUCTION}

Fisheries worldwide are experiencing a general failure of many widely used management systems; roughly $76 \%$ of the 441 stocks or species groups assessed can be considered fully exploited or depleted, while only $3 \%$ are underexploited (Csirke 2005). The main causes of such failure are intrinsically linked to the high uncertainty associated with the different steps of any fisheries management process, including the variability and complexity of marine ecosystems, the dynamic nature of fish populations, the impact of fishing activities, and the difficulties in achieving adequate monitoring and harvesting control in marine fisheries (Harwood \& Stokes 2003).

In the Mediterranean Sea, fisheries management must cope with the particularly high complexity and heterogeneity of fish habitats and a high number of commercial fish species and by-catches (Bianchi \&
Morri 2000). Fisheries are dominated by small and medium-sized vessels dissipated along the coasts and operating with a wide array of fishing gears (Lleonart 2005). Almost all management strategies in this context are limited to the control of fishing capacity or to the application of technical measures, like mesh size regulation, establishment of a minimum landing size and closures of areas and seasons for fishing.

Although Mediterranean fisheries have shown a surprisingly high resilience to human exploitation compared to some Atlantic fisheries, the most important commercial species are now fully exploited or overexploited (Lleonart 2005), and important negative impacts have also been measured at the level of habitats and communities (Tudela 2004). To address these problems, the scientific community is currently evaluating the introduction in the Mediterranean of the socalled ecosystem approach to fisheries (EAF), which should supply the necessary tools to protect and 
restore ecosystems, including commercial species and their habitats, with the ultimate objective of ensuring the sustainability of fisheries in the long term (Goñi et al. 2000, Pauly et al. 2002).

The Council Regulation of the European Community (EC reg. no. 1967/2006) provides some guidelines for the implementation of EAF in the Mediterranean, with particular attention devoted to the protection of nursery areas. The regulation has the potential to yield important conservation benefits and is based on 2 assumptions: (1) juvenile fish are particularly vulnerable to fine mesh trawl fishery (Caddy 1993), especially when they concentrate in nursery areas, and (2) a reduction in fishing mortality of immature fish represents a fundamental prerequisite for sustainable fisheries (Beverton \& Holt 1957).

The implementation of management measures aimed at reducing the effects of fishing on juveniles and their habitats requires the spatial identification of nurseries. Usually, any area where juveniles occur in relatively high densities has been considered as a nursery (Dahlgren et al. 2006) but without providing a clear definition. Some recent attempts to establish a definition of nurseries within a general conservation framework have been developed mainly for coastal species. Beck et al. (2001) defined a nursery as a habitat that, compared to other habitats on a per-unit-area basis, gives a greater contribution to the adult population of a given species; Dahlgren et al. (2006) introduced the concept of Effective Juvenile Habitats, referring to habitats that make a greater than average overall contribution to the adult population. Many authors agree that the most effective way of assessing the importance of a specific habitat in terms of juvenile production is to directly measure the movement of individuals from juvenile habitats to the adult population (Beck et al. 2001, Gillanders et al. 2003). This strategy has been applied mainly to coastal species, using different techniques from mark-recapture (Pihl \& Ulmestrand 1993) to analyses of trace elements in fish otoliths (Tomás et al. 2006). Most of these techniques, however, cannot be applied to large populations of deep-water species, whose nurseries are often located on deep continental shelves or upper slopes, as is the case with the European hake Merluccius merluccius, which, after a larval planktonic stage, settles down over the shelf-break (between 100 and $200 \mathrm{~m}$ in depth; Fiorentino et al. 2003, Colloca et al. 2004). Estimating the contribution of nurseries to the adult population of this species would require large field experiments, often far beyond the current economic possibilities of most national research systems.

As a practically feasible alternative we suggest that the spatial abundance of juvenile fish and the persistence over time of density hot-spots can be used to identify nursery areas. Our approach is based on the assumption that the average contribution to the adult population can be expected to be higher for nurseries with higher juvenile density and higher spatio-temporal stability. In fact, maintenance of a population depends on successful recruitment of young fish to nursery areas and from nursery areas back to the parent population (Hinckley et al. 2001). The location of nursery areas is therefore an integral component of the adaptation of marine fish life cycles to their environments. In this context, the stability of a density hot-spot of fish juveniles in a given area can be assumed to be indirect evidence of the importance of that area to the recruitment success of the population. Furthermore, the temporal persistence of the characteristics of an area is a fundamental prerequisite for its inclusion in a conservation network, as commonly considered in terrestrial ecosystems (Early et al. 2008).

We propose a 3-step approach to identify and classify nursery areas for conservation purposes. In particular, using European hake as a model species, we (1) estimated the distribution of juvenile densities using Bayesian kriging (Diggle \& Ribeiro 2007) and trawl survey data, (2) identified density hot-spots using geostatistical accumulation curves and (3) produced measures of persistence to identify nurseries.

We selected hake as a case study because it is among the most important commercial species in the Mediterranean, suffering from high fishing pressure and currently overexploited (Lleonart 2005). Standard assessments indicated the need for drastic reduction of the fishing mortality in juveniles, which are particularly exposed to trawl fishery after the bottom settlement stage, when they congregate over nursery grounds (Aldebert et al. 1996).

\section{MATERIALS AND METHODS}

Study area and trawl survey data. We considered $42410 \mathrm{~km}^{2}$ off the central-western coast of Italy, corresponding to the FAO fisheries management geographical sub-area 9 (central-western Tyrrhenian and Ligurian Seas; Fig. 1). Data on juvenile hake density were collected during 2 different trawl survey projects, the EU-funded MEDIterranean Trawl Survey (MEDITS; Bertrand et al. 2002), carried out in spring to early summer (May to July) and the GRUppo Nazionale Demersali (GRUND; Relini 1998), conducted in autumn. MEDITS started in 1994 and was carried out every year and GRUND was carried out from 1985 to 1987 and from 1996 to 2006 (no data available for 1999). Both projects used a stratified sampling design based on depth (5 bathymetric strata: 10-50, 51-100, 101-200, 201-500 and 501-700 m) and geographical 


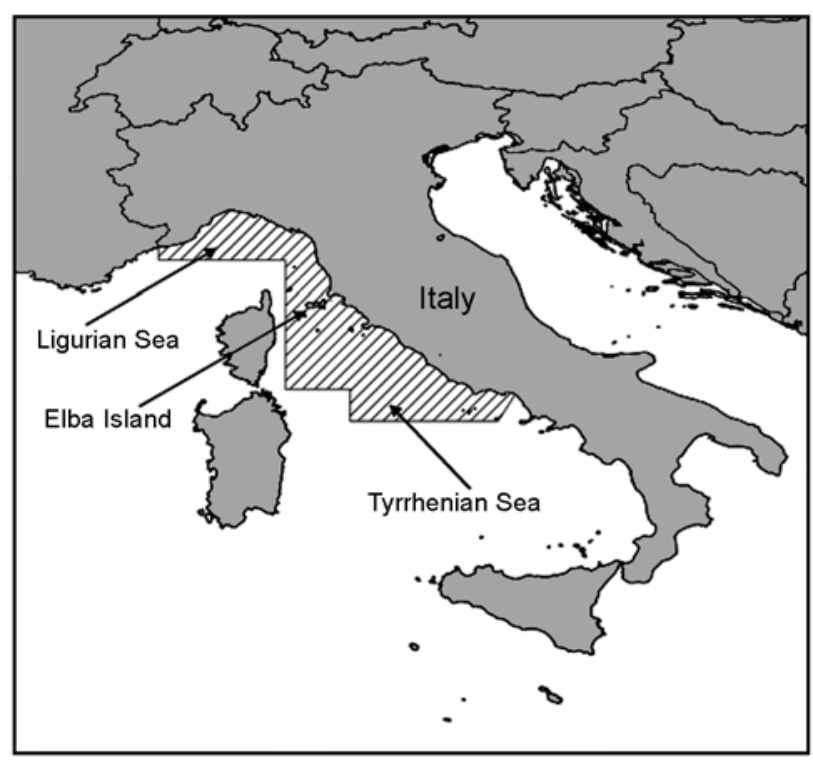

Fig. 1. Study area

sub-area. Depth strata were adopted to cover as much as possible of the distribution ranges of the species commercially exploited or potentially exploitable in each geographical sub-area. Sampling stations (153 for MEDITS and 210 for GRUND) were placed randomly within each stratum at the beginning of the projects and were sampled in all subsequent years. Each haul, conducted during daytime hours (06:00 to 18:00 h), lasted from $30 \mathrm{~min}$ (hauls up to $200 \mathrm{~m}$ in depth) to 60 min (hauls below $200 \mathrm{~m}$ in depth) for MEDITS, and $60 \mathrm{~min}$ for GRUND. The towing speed of the vessels was about $5.6 \mathrm{~km} \mathrm{~h}^{-1}$ for both projects. The distance covered by the net on the bottom was calculated with a Global Positioning System (GPS).

The area swept in each haul, calculated from direct measurements of the horizontal opening of the net detected by SCANMAR equipment, ranged between 0.03 and $0.18 \mathrm{~km}^{2}$, according to the depth and the duration of the hauls.

We included in the analyses all available data from both MEDITS and GRUND collected from the 1980s to 2004. For each haul, we calculated inds. $\mathrm{km}^{-2}$, considering only hake recruits, defined as those individuals less than $14 \mathrm{~cm}$ in total length (Bartolino et al. 2008).

Estimating spatial distribution of juvenile hake. We adopted a Bayesian kriging model (Diggle \& Ribeiro 2007) to calculate a pair of density estimates for each year (an early summer estimate based on MEDITS and an autumn estimate based on GRUND) over a $2 \mathrm{~km} \times$ $2 \mathrm{~km}$ estimation grid covering the whole study area (7290 cells). Data from all hauls were $\log (y+1)$ transformed to improve normality.

A prerequisite of any Bayesian analysis is the choice of prior distributions to be used for the estimation of model parameters (McCarthy \& Masters 2005). Given a time series of survey data, an earlier survey can provide informed priors for the calculation of the posterior parameter distribution covering the entire time span considered (Fig. 2).

We used the available data from the 1980s to build an informative prior structure for the early summer estimation of 1994. In the subsequent step of our estimation chain, the estimated 1994 posterior distribution was used to define the prior for the following year, and we proceeded in the same way for all early summer surveys, building an estimation chain from 1995 to 2004. Starting from 1996, we also used the early summer estimated posterior distributions to define the prior distribution for the autumn survey data (Fig. 2), building a second estimation chain from 1996 to 2004.

The 2 estimation chains described above are based on the assumption that the spatial distribution and abundance of juvenile hake in early summer are highly indicative of the distribution and abundance of juvenile hake in autumn of the same year and in the early summer of the subsequent year. A pattern of this type can be generated by the usual recruitment dynamics of hake in the central Mediterranean Sea. In fact, a main recruitment event occurs in winter-spring (Belcari et al. 2006), and then the spatial distribution of recruits remains constant for the following 6 to 10 mo

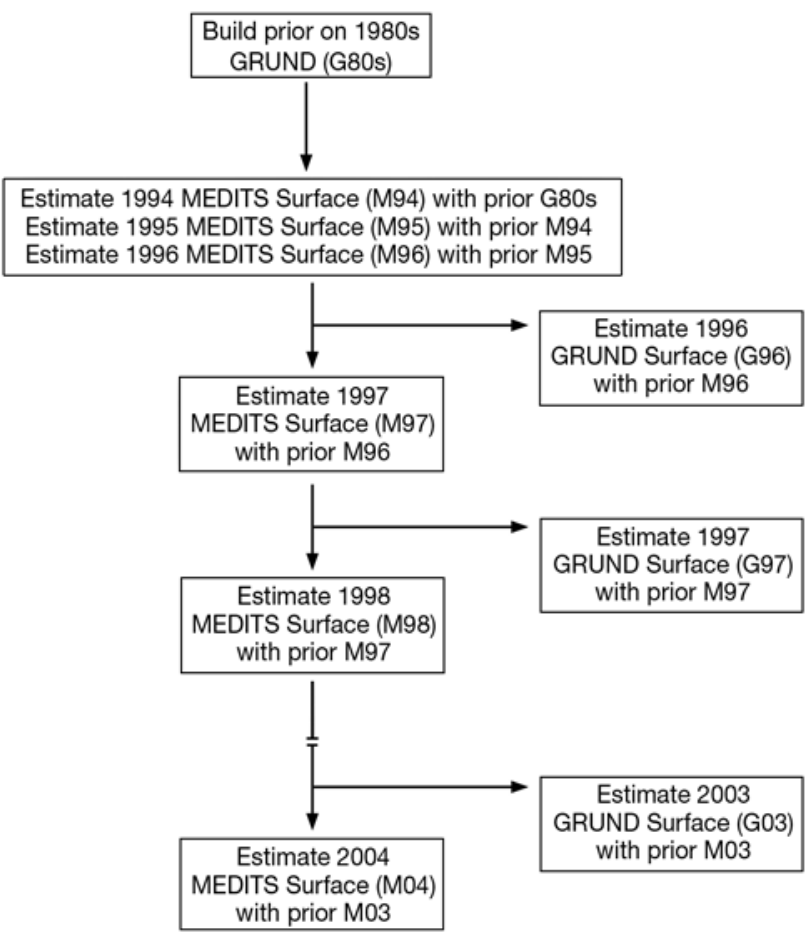

Fig. 2. Bayesian estimation procedure used to map juvenile hake in the central Mediterranean Sea employing trawl survey density data (inds. $\mathrm{km}^{-2}$ ) 
(Bartolino et al. 2008). This implies that every year the 2 surveys (MEDITS and GRUND) sampled the same age class at 2 time intervals. In contrast, distribution and abundance measured in autumn are not necessarily indicative of the distribution and abundance during early summer of the following year, because a new recruitment event has occurred between the GRUND and MEDITS surveys.

The general model structure that we adopted can be formalised mathematically as:

$$
Y(s)=\mu(s)+\varepsilon(s)
$$

where $Y(s)$ is the observed value at location $s, \mu(s)$ is the spatial trend (or large-scale variation), and $\varepsilon(s)$ is the small-scale variation (Cressie 1993). We performed an exploratory analysis of spatial variability considering first- and second-order trend models. A first-order model was selected because the second-order model absorbed most of the spatial variation (trend overfitting). The choice of a linear trend was also supported by a maximum likelihood ratio test (performed for each year and each survey) that clearly demonstrated no significant difference $(p>0.05)$ between first- and second-order models.

To explore possible differences in the spatial structure in our entire estimation chain, we performed an exploratory analysis, calculating for each year and for each survey an empirical variogram, formalised mathematically as:

$$
\gamma(h)=\frac{1}{2 n(h)} \frac{1}{n} \sum_{k=1}^{n} \delta_{i j}\left[y\left(s_{i}\right)-y\left(s_{i}+h\right)\right]^{2}
$$

where $\gamma(h)$ is the experimental variogram for distance $h, n(h)$ is the number of points separated by distance $h$, and $y\left(s_{i}\right)$ is the fish density value at point $s_{i}$. A monotonic increase of the variogram with increasing distance separating the sampling locations indicates the presence of a spatial autocorrelation (Cressie 1993). The exploratory analysis, performed using the geoR library of the R statistical software (R Development Core Team 2007), confirmed a relatively stable spatial structure. In particular, we fitted different variogram models (exponential, spherical, Gaussian) using maximum likelihood (Cressie 1993), and the combination of an exponential variogram model with a first-order trend provided the best results in terms of cross-validation and the Bayesian Information Criterion (Schwarz 1978).

Identifying density hot-spots. To identify areas that host high annual densities of juvenile hake (i.e. annual nursery areas), we built a geostatistical aggregation curve for the estimated spatial distribution of each early summer and autumn. Geostatistical aggregation curves were originally defined by Matheron (1981), and subsequently elaborated by Petitgas (1998), to describe spatial distribution changes as a function of variations in population abundance. Here we used geostatistical aggregation curves to identify annual nursery areas.

A geostatistical aggregation curve relates the relative abundance of individuals $P(y)$ to the area $T(y)$ occupied by those individuals for densities greater than $y$. For calculation of the aggregation curve, all cells are ranked according to their density from maximum to minimum. Along this gradient, it is possible to calculate for each cell the cumulative abundance as a proportion of the total abundance, $P(y)$, and the proportion of the total area, $T(y)$. Both $P(y)$ and $T(y)$ range from 0 to 1 , and the resulting curve describes the accumulation abundance with increasing area. $P(y)$ and $T(y)$ can be formalised mathematically as:

$$
\begin{aligned}
& P(y)=\sum_{i=1}^{k} \frac{n_{i}}{N} \\
& T(y)=\sum_{i=1}^{k} \frac{a_{i}}{A}
\end{aligned}
$$

where $n_{\mathrm{i}}$ is the number of fish in the density class $i, a_{i}$ is the area occupied by those fish for each class $i$ and $N$ is the total number of fish in the total area $A$.

We calculated a relative geostatistical aggregation curve $P(T)$ for each annual estimated spatial distribution combining Eqs. (3) \& (4). For each geostatistical aggregation curve, we identified the location where the tangent line to the curve had a $45^{\circ}$ slope. The tangent point was adopted as a threshold for the identification of nurseries over each annual estimated surface. Each curve up to the $45^{\circ}$ tangent point included a specific percentage of cells. This percentage was used to find the corresponding percentile of the estimated fish density distribution and thus the nursery density threshold (Fig. 3).

The geometrical properties of the $45^{\circ}$ tangent to the relative aggregation curve correspond to a change in the spatial distribution of fish from a dispersed distribution pattern to an aggregated pattern. For fish densities lower than the above identified threshold, a relative increase in the area is followed by a proportionally lower increase in the number of fish included. Conversely, above the threshold the relative increase is higher in the number of fish than in the area.

Persistence of nurseries. For each cell in the study area, we calculated an Index of Persistence $\left(I_{i}\right)$, measuring the relative persistence of the cell $i$ as an annual nursery (Fiorentino et al. 2003). Let $\delta_{i k j}=1$ if the grid cell $i$ is included in a nursery in year $j$ and in survey $k$, and $\delta_{i k j}=0$ otherwise. We computed $I_{i}$ as follows:

$$
I_{i}=\frac{1}{n} \sum_{k=1}^{n} \delta_{i j}
$$



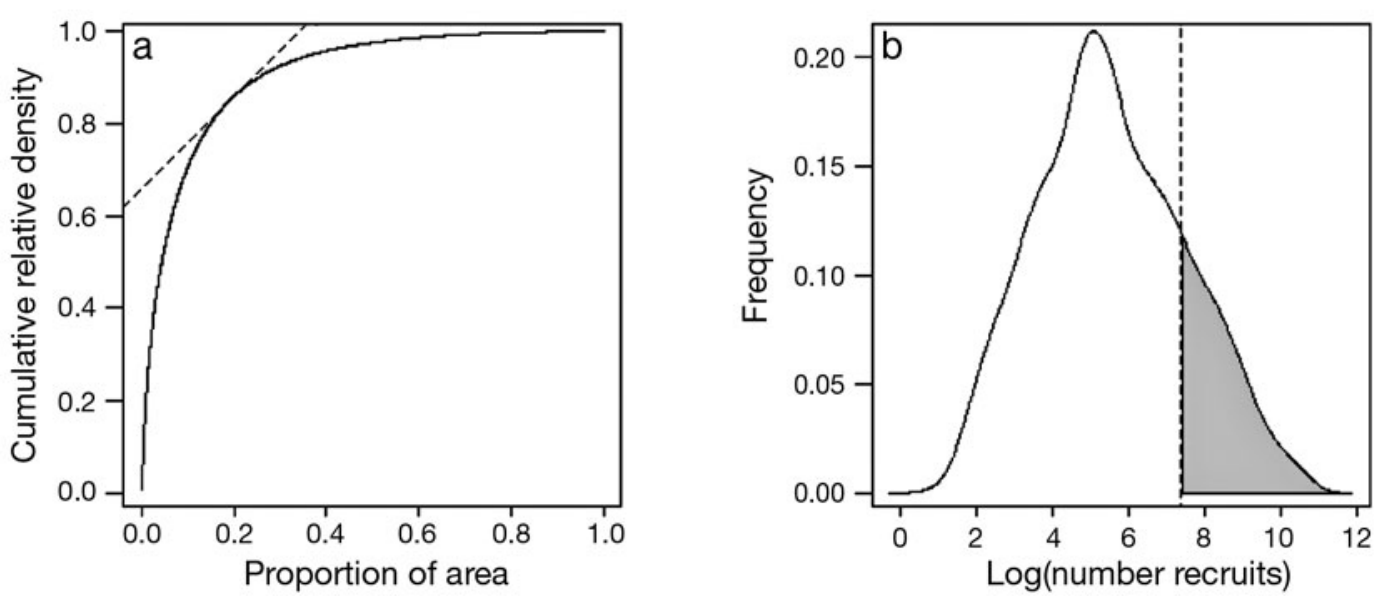

Fig. 3. Merluccius merluccius. (a) Relative geostatistical aggregation curve (cumulative relative density of hake juveniles versus proportion of study area) showing the tangent (dotted line) to the curve with $45^{\circ}$ slope. (b) Frequency distribution of estimated fish density with the related percentile (shaded area) corresponding to the proportion of cells above the identified density threshold

where $n$ is the number of surveys considered. $I_{i}$ ranges between 0 (cell $i$ never included in an annual nursery area) and 1 (cell $i$ always included in an annual nursery area) for each cell in the study area. Using different levels of $I_{i}$, we calculated the area occupied by nurseries and the proportion of hake recruits included in the nurseries.

\section{RESULTS}

\section{Spatial distribution of juvenile hake}

For the 1994 early summer estimate, we used the following prior settings: (1) variogram range with a uniform distribution (2 to $250 \mathrm{~km}$ with $1 \mathrm{~km}$ increments), (2) nugget to sill ratio fixed to 0 , (3) diffuse priors (Gaussian and inverse Gamma) for trend parameters and overall variance. All other estimates (both early summer and autumn) were based on early summer posterior estimates (of the previous year or of the same year, respectively) used as priors. Exponential variogram models had a nugget between 0 and 3.83, partial sill ranging from 4.88 to 15.17 , and range between 6.31 and $15.44 \mathrm{~km}$ (Table 1).

Juvenile hake distribution (Figs. 4 \& 5) was clearly patchy in all years considered, with a fairly consistent spatial pattern and with differences only in the size of the observed patches. The estimated average density of hake recruits showed large fluctuations throughout the sampling period, ranging from 300 fish $\mathrm{km}^{-2}$ (for MEDITS 1994) to 2479 fish km-2 (for MEDITS 1998). Recruit density also changed widely between the 2 surveys within the same year (Table 2).

\section{Distribution of density hot-spots}

The geostatistical aggregation curves showed a relatively stable spatial distribution pattern for hake in the

Table 1. Merluccius merluccius. Trend coefficients $\left(\beta_{0}, \beta_{1}, \beta_{2}\right)$ and variogram parameters (partial sill, range, nugget) estimated for hake recruits (log-densities) for MEDITS (early summer) and GRUND (autumn) surveys

\begin{tabular}{|c|c|c|c|c|c|c|}
\hline Year & $\beta_{0}$ & $\beta_{1}$ & $\beta_{2}$ & Partial sill & Range & Nugget \\
\hline \multicolumn{7}{|c|}{ MEDITS } \\
\hline 1994 & -27.106 & 0.010 & 0.005 & 7.358 & 12.831 & 2.616 \\
\hline 1995 & -27.106 & 0.010 & 0.005 & 7.358 & 12.831 & 2.616 \\
\hline 1996 & -67.300 & 0.015 & 0.013 & 11.456 & 14.376 & 0.798 \\
\hline 1997 & -36.190 & 0.011 & 0.007 & 12.035 & 11.349 & 0.000 \\
\hline 1998 & -7.241 & 0.007 & 0.001 & 12.077 & 15.447 & 1.481 \\
\hline 1999 & -38.756 & 0.007 & 0.008 & 15.176 & 9.529 & 0.000 \\
\hline 2000 & -3.742 & 0.006 & 0.001 & 12.909 & 9.547 & 0.000 \\
\hline 2001 & -25.281 & 0.012 & 0.004 & 10.036 & 8.876 & 0.000 \\
\hline 2002 & -13.631 & 0.005 & 0.003 & 11.559 & 7.588 & 0.000 \\
\hline 2003 & -11.967 & 0.004 & 0.003 & 14.247 & 12.086 & 0.000 \\
\hline 2004 & -22.935 & 0.006 & 0.005 & 12.367 & 11.498 & 0.000 \\
\hline \multicolumn{7}{|c|}{ GRUND } \\
\hline 1996 & -33.317 & 0.011 & 0.007 & 15.059 & 6.547 & 0.000 \\
\hline 1997 & -17.133 & 0.010 & 0.003 & 11.320 & 12.977 & 1.429 \\
\hline 1998 & -33.317 & 0.011 & 0.007 & 12.273 & 6.315 & 0.000 \\
\hline 2000 & -14.236 & 0.005 & 0.003 & 9.678 & 13.809 & 3.832 \\
\hline 2001 & 10.790 & -0.002 & -0.001 & 9.255 & 7.171 & 0.000 \\
\hline 2002 & -31.982 & 0.010 & 0.007 & 6.682 & 11.961 & 2.644 \\
\hline 2003 & 7.098 & 0.004 & -0.001 & 4.888 & 11.395 & 3.286 \\
\hline 2004 & 34.609 & -0.003 & -0.006 & 15.059 & 6.547 & 0.000 \\
\hline
\end{tabular}



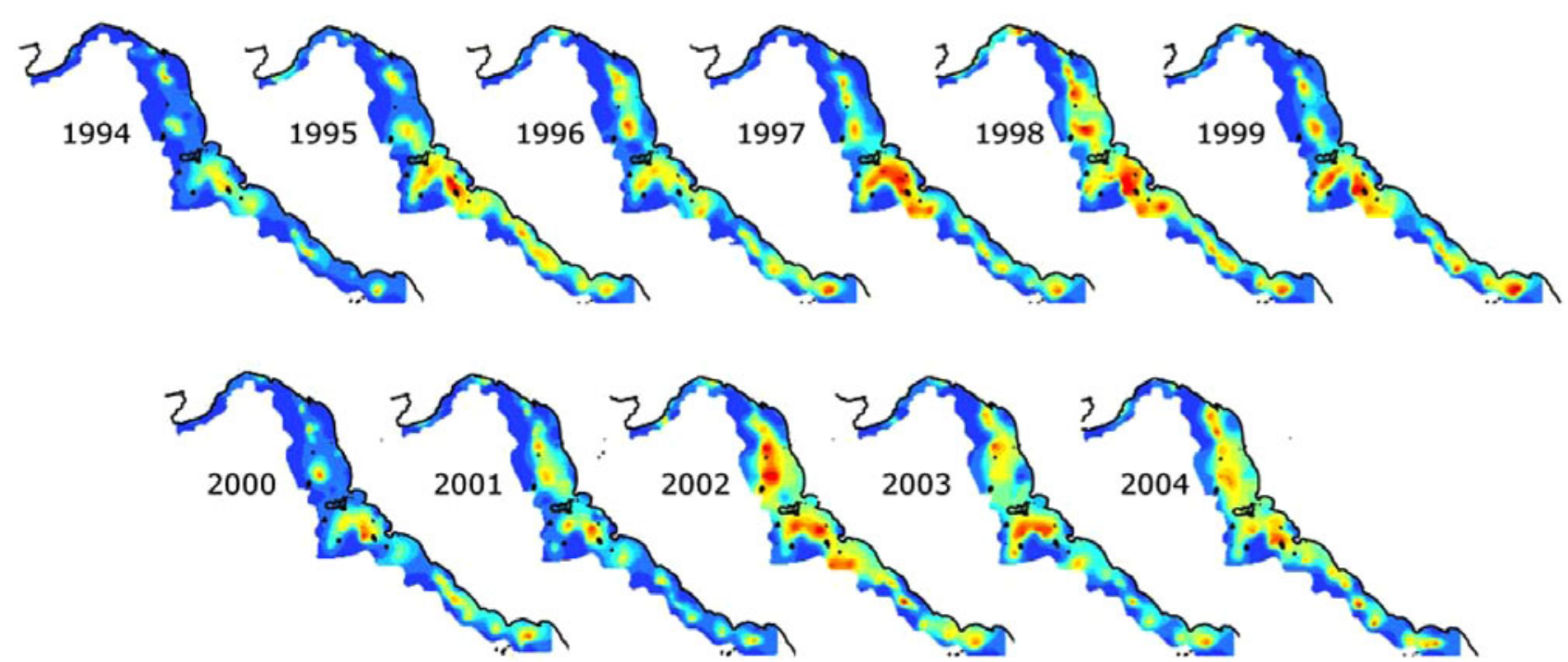

Hake density $\left(\mathrm{n} / \mathrm{km}^{2}\right)$

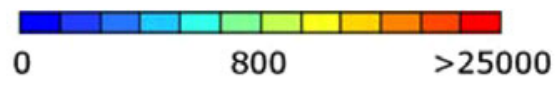

Fig. 4. Merluccius merluccius. Density maps of hake recruits based on the early summer MEDITS survey (1994 to 2004)

study area, despite the large density fluctuations from survey to survey. The curves clearly indicated a strong aggregation of recruits, with about $80 \%$ of them concentrated in 18 to $26 \%$ of the study area during early summer, and in 20 to $30 \%$ of the study area in autumn (Table 2, Fig. 6).

The different nursery thresholds varied between 245.9 and 3389.7 fish $\mathrm{km}^{-2}$ for the MEDITS survey, and between 568.3 and 2834.7 fish $\mathrm{km}^{-2}$ for the GRUND survey. The nurseries identified by these thresholds covered 18 to $30 \%$ of the total study area. The nurseries with the largest recruit density were located north (south Ligurian Sea) and south of the Isle of Elba (northern Tyrrhenian Sea), while smaller high-density patches were widespread along the
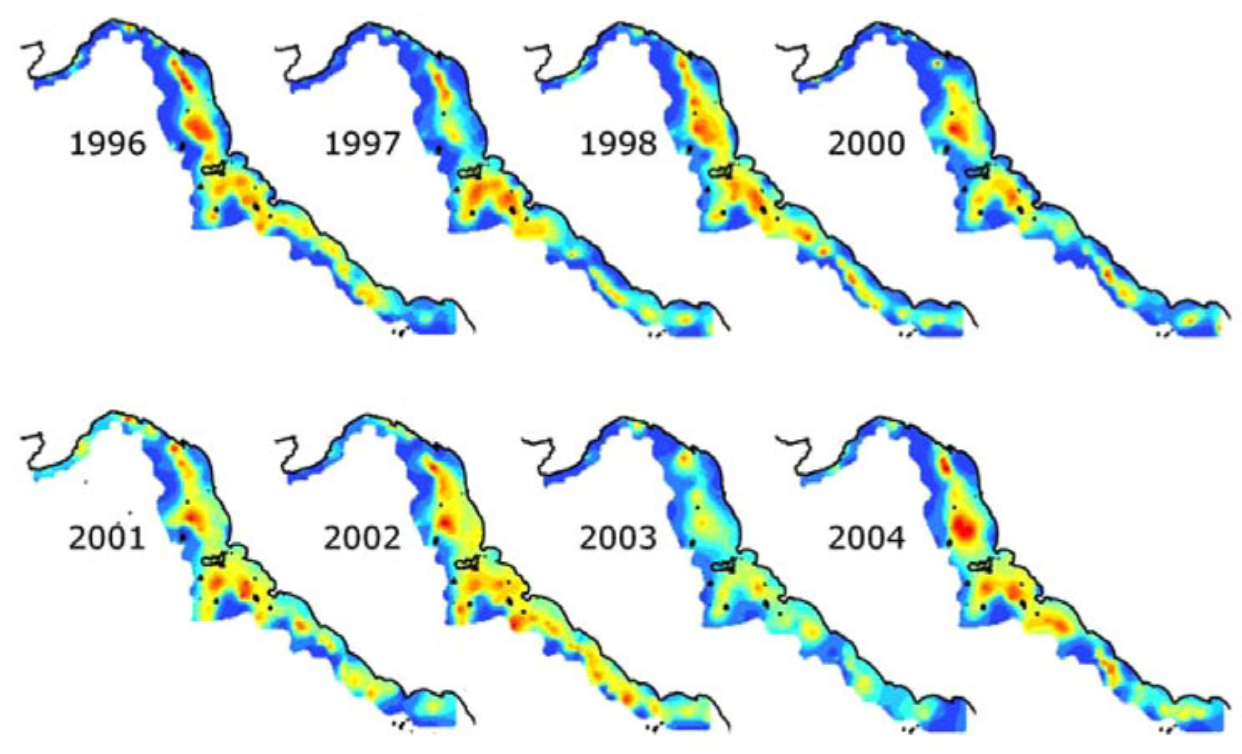

Hake density $\left(\mathrm{n} / \mathrm{km}^{2}\right)$

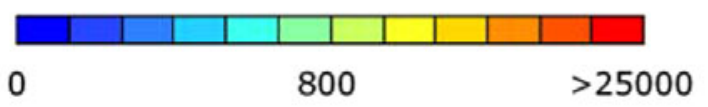

Fig. 5. Merluccius merluccius. Density maps of hake recruits based on the autumn GRUND survey (1996 to 2004) 
Table 2. Merluccius merluccius. Estimated size, percentage of the study area and percentage of recruits for the identified hake nurseries off the central-western coast of Italy. M: MEDITS survey (early summer), G: GRUND survey (autumn)

\begin{tabular}{|lccc|}
\hline Survey & $\begin{array}{c}\text { Nursery area } \\
\left(\mathrm{km}^{2}\right)\end{array}$ & $\begin{array}{c}\text { Study area } \\
(\%)\end{array}$ & $\begin{array}{c}\text { Recruits } \\
(\%)\end{array}$ \\
\hline $1994 \mathrm{M}$ & 4264 & 22.3 & 82.1 \\
$1995 \mathrm{M}$ & 6024 & 25.1 & 81.8 \\
$1996 \mathrm{M}$ & 5748 & 25.1 & 81.5 \\
$1996 \mathrm{G}$ & 6104 & 25.9 & 82.8 \\
$1997 \mathrm{M}$ & 4392 & 19.1 & 86.5 \\
$1997 \mathrm{G}$ & 5680 & 23.7 & 84.4 \\
$1998 \mathrm{M}$ & 5136 & 20.4 & 82.8 \\
$1998 \mathrm{G}$ & 6876 & 27.0 & 82.5 \\
$1999 \mathrm{M}$ & 4576 & 19.2 & 85.2 \\
$2000 \mathrm{M}$ & 3988 & 18.1 & 81.2 \\
$2000 \mathrm{G}$ & 5724 & 24.1 & 83.3 \\
$2001 \mathrm{M}$ & 4888 & 21.8 & 80.4 \\
$2001 \mathrm{G}$ & 6800 & 25.0 & 76.9 \\
$2002 \mathrm{M}$ & 5244 & 20.5 & 80.1 \\
$2002 \mathrm{G}$ & 8024 & 29.8 & 78.3 \\
$2003 \mathrm{M}$ & 4960 & 19.9 & 79.5 \\
$2003 \mathrm{G}$ & 7460 & 29.7 & 73.9 \\
$2004 \mathrm{M}$ & 6544 & 26.3 & 79.2 \\
$2004 \mathrm{G}$ & 5016 & 19.8 & 80.7 \\
\hline
\end{tabular}

shelf-break (120 to $250 \mathrm{~m}$ depth) across the entire study area (Figs. 4 \& 5).

\section{Nursery persistence}

The largest nursery areas showed a highly persistent core, surrounded by areas with lower persistence (Fig. 7). Smaller nurseries appeared sporadically along the shelf-break (150 to $250 \mathrm{~m}$ ). Different levels of per- sistence produced different scenarios in terms of proportion of recruits included within nursery areas. Highly persistent nurseries $\left(I_{i}>80 \%\right)$ covered $5.3 \%$ of the study area and included on average $39.2 \%$ of recruits (proportion calculated over the entire study period). Nurseries occurring in at least 60 to $80 \%$ of surveys included $12.4 \%$ of the whole area and $65.6 \%$ of recruits.

\section{DISCUSSION}

We proposed a conceptual and methodological framework for the identification of fish nurseries on the basis of their spatio-temporal persistence, which can be helpful when quantitative data on the contribution of nursery habitats to the adult population are lacking.

We applied our approach to hake recruits, using density data collected during $10 \mathrm{yr}$ of trawl surveys in the central Mediterranean Sea (central-western coast of Italy). Trawl surveys represent one of the most important sources of data for the study of demersal fish (Bertrand et al. 2002), despite the inevitable inherent biases that characterise these datasets. A number of different methods are available for obtaining unbiased indices of abundance that account for trawl survey design, spatial autocorrelation and other spatial patterns and processes (Stefánsson 1996, Petitgas 2001). However, the application of geostatistical methods to such data to map species distribution (e.g. Maravelias et al. 1996) is often hampered by the low number of sampling stations relative to the area surveyed. Groundfish surveys tend to be spatially constrained because of high ship costs, and the resulting sampling points are usually scattered, with large areas that are
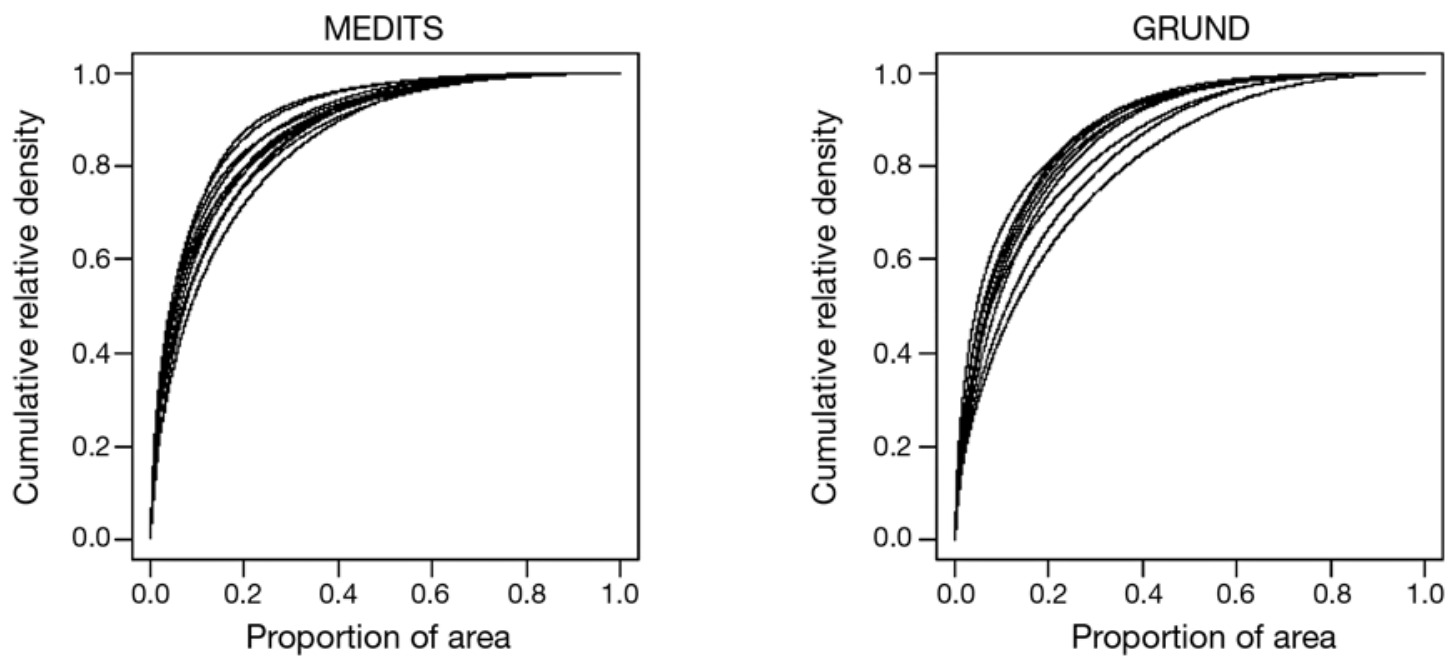

Fig. 6. Merluccius merluccius. Relative geostatistical aggregation curves (cumulative relative density of hake juveniles versus proportion of study area) for the early summer (MEDITS) and autumn (GRUND) estimations 


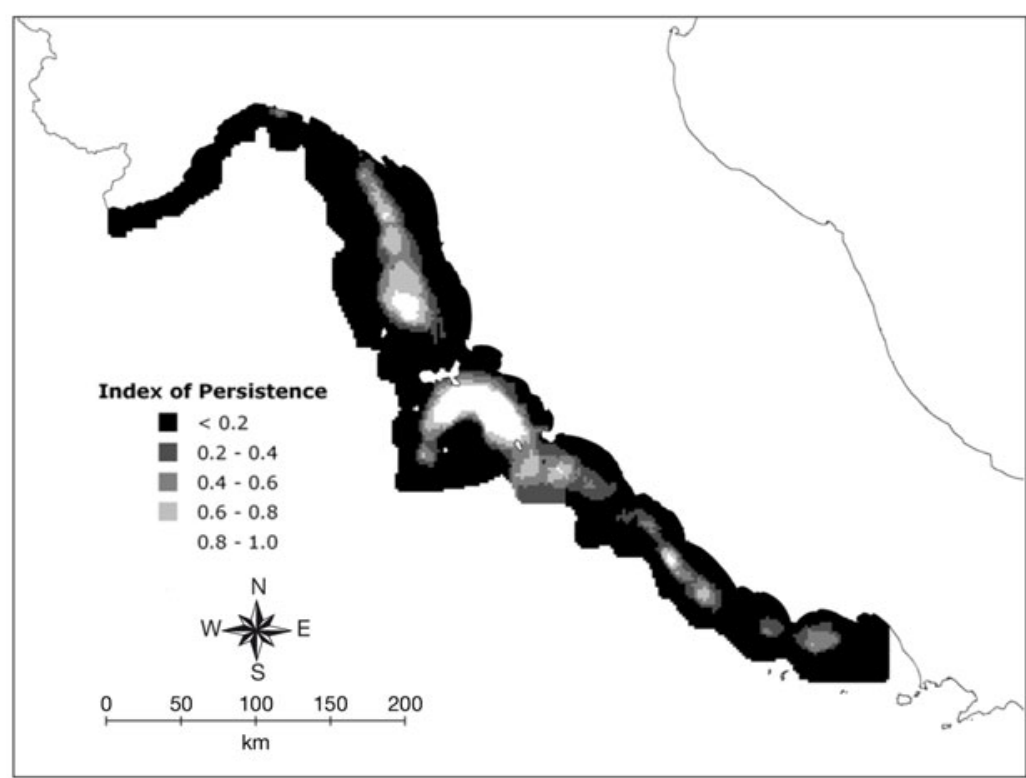

Fig. 7. Temporal persistence of the estimated nurseries in the period 1994 to 2004 , based on data from the early summer and autumn surveys

the potential of our approach for providing a simple alternative to traditional methods used for the spatial identification of hot-spots (Nelson \& Boots 2008).

The spatial distribution of juvenile hake was similar to that already described in the same area through different mapping techniques (Ardizzone \& Corsi 1997, Abella et al. 2005). Juvenile hake were patchily distributed around the shelf-break (150 and $250 \mathrm{~m}$ depth) and showed stable density hot-spots, which can be regarded as nursery areas, covering 18 to $30 \%$ of the study area, depending on the season and year considered. Three major physical processes explain the temporal stability of these high-density areas: (1) enrichment (e.g. upwelling, water mixing), (2) concentration (convergence, frontal formation, water column stability) and (3) retention within (or drift toward) appropriate habitat ('ocean triad'; Bakun 1998). In the

not sampled. As a consequence, the variance associated with any index calculated through survey data is often extremely large, as is the uncertainty related to any spatial prediction (Rufino et al. 2006). In addition, the spatial distribution pattern of fish species is continuously changing as a consequence of density-dependent (MacCall 1990) and density-independent factors (Shepherd \& Litvak 2004), with the latter generating large fluctuations in local abundance.

In classical geostatistical applications, the full range of uncertainties that is always associated with species distribution models is not correctly measured, as many parameters that are considered to be 'known' are actually estimated through the statistical model (Diggle \& Ribeiro 2007), a potential cause of optimistic assessments of predictive accuracy. Using Bayesian kriging, we incorporated parameter uncertainty into the prediction process by treating the parameters as random variables. Even though our framework did not solve all problems linked to the lack of data, the existence of spatial clusters or variations in density-dependent and density-independent factors. Bayesian kriging has been increasingly used in ecological research (McCarthy \& Masters 2005) to take advantage of biologically sound prior information.

For the identification of hot-spots of juvenile hake density, we coupled the Bayesian kriging estimates together with an innovative analysis of geostatistical accumulation curves. Previous studies that used the same technique focused on the analysis of spatial distribution changes in relation to variation in population abundance (Petitgas 2009). We clearly demonstrated
Tyrrhenian and Ligurian Seas, both eddies and frontal systems retain larvae and juveniles of hake in areas of relatively high production (Abella et al. 2008), characterised by the occurrence of high biomass of macroepibenthic suspension feeders, such as crinoids (Colloca et al. 2004). A stable temporal pattern of hake nurseries was similarly observed in the Strait of Sicily (Fiorentino et al. 2003).

We considered the stability in space and time of high-density areas to be a useful measure to evaluate their importance as nurseries. Similarly, Fodrie \& Levin (2008) showed that juvenile distribution over time was a good indicator of unit-area productivity of nursery areas of California halibut Paralichthys californicus.

The high spatial stability in time of the main hake nurseries can also represent a valuable feature for conservation and management purposes, ensuring, for instance, long-term effectiveness of no-take areas. In our study area, the closure of highly persistent nurseries $(I=80$ to $100 \%)$ would result in a small reduction of the exploitable fishery area $(5.3 \%)$ and the protection of a considerable fraction $(39.2 \%)$ of the total estimated recruits. The impact on local fisheries of these measures could also be limited, given that the operating fleet does not concentrate on hake nursery areas owing to the high discard rate that trawling in these areas would imply (Abella et al. 2005). Using a theoretical model for European hake in the Mediterranean, Apostolaki et al. (2002) found that nursery protection led to an increase in resilience to fishing and in yields even when juvenile fish were targeted. 
However, it is clear that other factors must be incorporated in any analysis aimed at quantitatively assessing the implications of no-take areas for fisheries. They include the effect of these areas on hake and other fish populations, also because of the reallocation of fishing effort after their establishment (Murawsky et al. 2005), and the economic consequences of no-take areas and their management plans (Edwards et al. 2009). Knowledge of the spatial and temporal distribution of juvenile fish is essential to closing the lifecycle in population dynamics models, and it is a prerequisite for the identification of spatial measures aimed at the protection of juveniles (Hinrichsen et al. 2009).

The analytical approach that we used here to document the persistence of spatial patterns in the distribution of juvenile hake can be extended to different species and life stages to improve knowledge of the role of habitat for populations and communities. This kind of information can be combined with data on the distribution of fishing fleets and with multiple species datasets (Maiorano et al. 2009) for an effective ecosystem approach to fisheries management in the Mediterranean.

Acknowledgements. This research was carried out within the framework of the BECAUSE project (Critical Interactions BEtween Species and their Implications for a PreCAUtionary FiSheries Management in a variable Environment - a Modelling Approach), EU contract no. 502482. We thank 3 anonymous referees for their comments on a previous version of the manuscript, which improved it considerably.

\section{LITERATURE CITED}

Abella A, Serena F, Ria M (2005) Distributional response to variations in abundance over spatial and temporal scales for juveniles of European hake (Merluccius merluccius) in the Western Mediterranean Sea. Fish Res 71:295-310

Abella A, Fiorentino F, Mannini A, Orsi Relini L (2008) Exploring relationships between recruitment of European hake (Merluccius merluccius L. 1758) and environmental factors in the Ligurian Sea and Strait of Sicily (Central Mediterranean). J Mar Syst 71:279-293

Aldebert Y, Recasens L, Lleonart J (1996) Comparison of methods for stock assessment of European hake Merluccius merluccius in the Gulf of Lions (Northwestern Mediterranean). Aquat Living Resour 9:13-22

Apostolaki P, Milner-Gulland EJ, McAllister MK, Kirkwood GP (2002) Modelling the effects of establishing a marine reserve for mobile fish species. Can J Fish Aquat Sci 59:405-415

Ardizzone GD, Corsi F (1997) Atlas of Italian demersal fishery resources. Biol Mar Mediterr 4:1-568

Bakun A (1998) Ocean triads and radical interdecadal stock variability: bane and boon for management science. In: Pitcher TJ, Hart PJB, Pauly D (eds) Reinventing fisheries management. Kluwer Academic Publishers, London, p 331-358

Bartolino V, Ottavi A, Colloca F, Ardizzone GD, Stefansson G (2008) Bathymetric preferences in hake juveniles (Merluccius merluccius). ICES J Mar Sci 65:963-969
Beck MW, Heck KL Jr, Able KW, Childers DL and others (2001) The identification, conservation, and management of estuarine and marine nurseries for fish and invertebrates. Bioscience 51:633-641

> Belcari P, Ligas A, Viva C (2006) Age determination and growth of juveniles of the European hake, Merluccius merluccius (L., 1758), in the northern Tyrrhenian Sea (NW Mediterranean). Fish Res 78:211-217

Bertrand JA, Gil De Sola L, Papacostantinou C, Relini G, Souplet A (2002) The general specifications of the Medits survey. Sci Mar 66:9-17

Beverton RJH, Holt SJ (1957) On the dynamics of exploited fish populations. Fishery investigations, Series 2. Ministry of Agriculture and Fisheries, London

Bianchi CN, Morri C (2000) Marine biodiversity of the Mediterranean Sea: situation, problems, and prospects for future research. Mar Pollut Bull 40:367-376

Caddy JF (1993) Some future perspectives for assessment and management of Mediterranean fisheries. Sci Mar 57: 121-130

Colloca F, Carpentieri P, Balestri E, Ardizzone GD (2004) A critical habitat for Mediterranean fish resources: shelf break areas with Leptometra phalangium (Echinodermata, Crinoidea). Mar Biol 145:1129-1142

Cressie N (1993). Statistics for spatial data. Wiley, New York

Csirke J (2005) Global production and state of marine fishery resources. In: Review of the state of world marine fishery resources. FAO Fish Tech Pap 457, Rome, p 1-9

> Dahlgren CP, Kelliston GT, Adams AJ, Gillanders BM and others (2006) Marine nurseries and effective juvenile habitats: concepts and applications. Mar Ecol Prog Ser 312: 291-295

Diggle PJ, Ribeiro PJ (2007) Model-based geostatistics series. Springer, New York, NY

Early R, Anderson B, Thomas CD (2008) Using habitat distribution models to evaluate large-scale landscape priorities for spatially dynamic species. J Appl Ecol 45:228-238

> Edwards CTT, Rademeyer RA, Butterworth DS, Plagányi ÉE (2009) Investigating the consequences of Marine Protected Areas for the South African deep-water hake (Merluccius paradoxus) resource. ICES J Mar Sci 66:72-81

Fiorentino F, Garofalo G, De Santi A, Bono G, Giusto GB, Norrito G (2003) Spatio-temporal distribution of recruits (0 group) of Merluccius merluccius and Phycis blennoides (Pisces, Gadiformes) in the Strait of Sicily (Central Mediterranean). Hydrobiologia 503:223-236

Fodrie FJ, Levin LA (2008) Linking juvenile habitat utilization to population dynamics of California halibut. Limnol Oceanogr 53:799-812

Gillanders BM, Able KW, Brown JA, Eggleston DB, Sheridan PF (2003) Evidence of connectivity between juvenile and adult habitats for mobile marine fauna: an important component of nurseries. Mar Ecol Prog Ser 247:281-295

Goñi R, Polunin NVC, Planes S (2000) The Mediterranean: marine protected areas and the recovery of a large marine ecosystem. Environ Conserv 27:95-97

Harwood J, Stokes K (2003) Coping with uncertainty in ecological advice: lessons from fisheries. Trends Ecol Evol 18:617-622

Hinckley S, Hermann AJ, Mier KL, Megrey BA (2001) Importance of spawning location and timing to successful transport to nursery areas: a simulation study of Gulf of Alaska walleye pollock. ICES J Mar Sci 58:1042-1052

> Hinrichsen HH, Kraus G, Böttcher U, Köster F (2009) Identifying eastern Baltic cod nursery grounds using hydrodynamic modelling: knowledge for the design of Marine Protected Areas. ICES J Mar Sci 66:101-108 
Lleonart J (2005) Mediterranean and Black Sea. In: Review of the state of world marine fishery resources. FAO Fish Tech Pap 457, Rome, p 49-64

MacCall AD (1990) Dynamic geography of marine fish populations. University of Washington Press, Seattle, WA

Maiorano L, Bartolino V, Colloca F, Abella A and others (2009) Systematic conservation planning in the Mediterranean: a flexible tool for the identification of no-take marine protected areas. ICES J Mar Sci 66:137-146

Maravelias CD, Reid DG, Simmonds EJ, Haralabous J (1996) Spatial analysis and mapping of acoustic survey data in the presence of high local variability: geostatistical application to North Sea herring (Clupea harengus). Can J Fish Aquat Sci 53:1497-1505

Matheron G (1981) La sélectivité des distributions, note N686. Centre de Géostatistique. Ecole des Mines de Paris, Fontainebleau

> McCarthy M, Masters P (2005) Profiting from prior information in Bayesian analyses of ecological data. J Appl Ecol 42:1012-1019

Murawsky SA, Wigley SE, Fogarty MJ, Rago PJ, Mountain DG (2005) Effort distribution and catch patterns adjacent to temperate MPAs. ICES J Mar Sci 62:1150-1167

Nelson TA, Boots B (2008) Detecting spatial hot spots in landscape ecology. Ecography 31:556-566

Pauly D, Christensen V, Guénette S, Pitcher TJ and others (2002) Towards sustainability in world fisheries. Nature 418:689-695

Petitgas P (1998) Biomass-dependent dynamics of fish spatial distributions characterized by geostatistical aggregation curves. ICES J Mar Sci 55:443-453

Petitgas P (2001) Geostatistics in fisheries survey design and stock assessment: models, variances and applications. Fish Fish 2:231-249

Editorial responsibility: Jake Rice,

Ottawa, Canada
Petitgas P (2009) Geostatistics and their applications to fisheries survey data: a history of ideas, 1990-2007. In: Megrey BA, Moksness E (eds) Computers in fisheries research. Springer, p 191-224

Pihl L, Ulmestrand M (1993) Migration pattern of juvenile cod (Gadus morhua) on the Swedish west coast. ICES J Mar Sci 50:63-70

R Development Core Team (2007) R: A language and environment for statistical computing. R Foundation for Statistical Computing, Vienna. Available online at: www.R-project. org

Relini G (1998) Demersal trawl surveys in Italian seas: a short review. Actes Colloq IFREMER 26:46-75

Rufino MM, Stelzenmüller V, Maynou F, Zauke GP (2006) Assessing the performance of linear geostatistical tools applied to artificial fisheries data. Fish Res 82:263-279

Schwarz G (1978) Estimating the dimension of a model. Ann Stat 6:461-464

Shepherd TD, Litvak MK (2004) Density-dependent habitat selection and the ideal free distribution in marine fish spatial dynamics: considerations and cautions. Fish Fish 5:141-152

Stefánsson G (1996) Analysis of groundfish survey abundance data: combining the GLM and delta approaches. ICES J Mar Sci 53:577-588

Tomás J, Geffen AJ, Millner RS, Piñeiro CG, Tserpes G (2006) Elemental composition of otolith growth marks in three geographically separated populations of European hake (Merluccius merluccius). Mar Biol 148: 1399-1413

Tudela S (2004) Ecosystem effect of fishing in the Mediterranean: an analysis of the major threats of fishing gear and practices to biodiversity and marine habits. In: FAO Studies and Review 74, Rome, p 1-44

Submitted: November 14, 2008; Accepted: January 22, 2009 Proofs received from author(s): March 31, 2009 